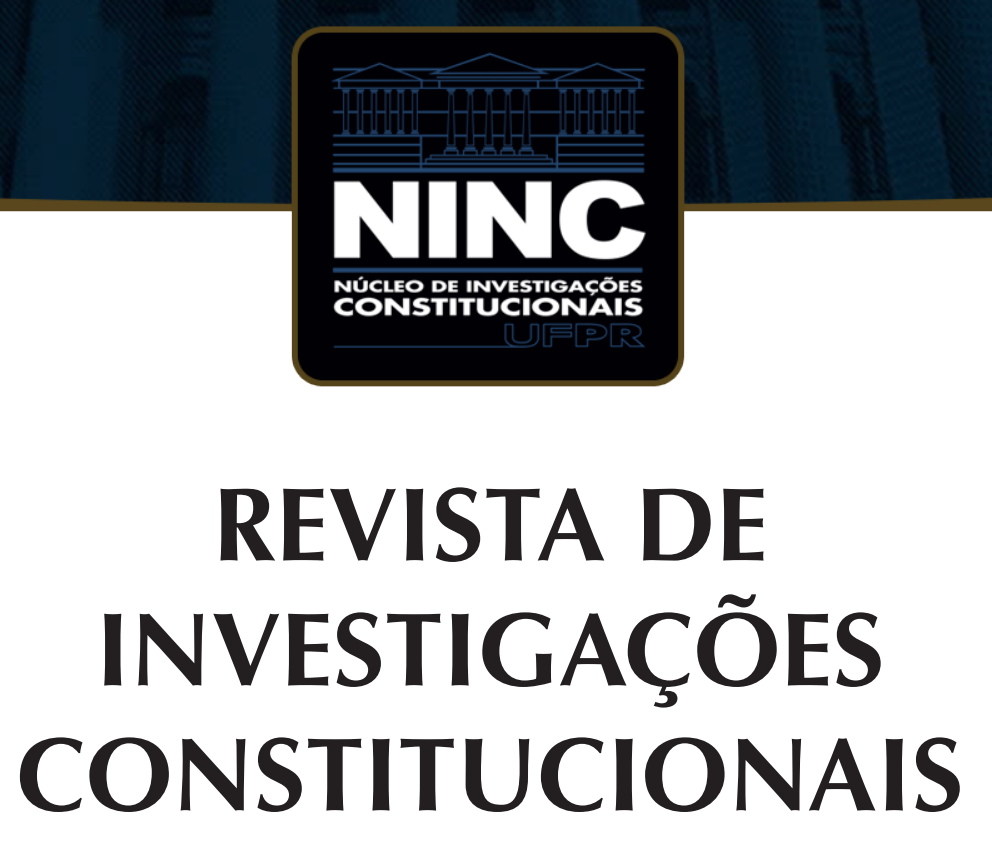

JOURNAL OF CONSTITUTIONAL RESEARCH

vol. 5 | n. 3 | setembro/dezembro 2018 | ISSN 2359-5639 | Periodicidade quadrimestral Curitiba | Núcleo de Investigações Constitucionais da UFPR | www.ninc.com.br 


\title{
30 anos da Constituição brasileira de 1988 e 5 anos da Revista de Investigações Constitucionais
}

\section{0 years of the Brazilian Constitution of 1988 and 5 years of the Journal of Constitutional Research}

\author{
"Repito: essa será a Constituição cidadã, porque \\ recuperará como cidadãos milhões de brasileiros, \\ vítimas da pior das discriminações: a miséria. \\ (...) \\ Viva a Constituição de 1988! \\ Viva a vida que ela vai defender e semear!" \\ (Ulysses Guimarães, Presidente da Assembleia \\ Nacional Constituinte de 1987-1988)
}

O trecho acima transcrito, extraído de um dos discursos de Ulysses Guimarãres, Presidente da Assembleia Nacional Constituinte de 1987-1988, bem demonstra a aposta que o povo brasileiro fez no projeto constitucional que então vinha à luz, depositando as esperanças na construção de uma sociedade democrática e regida por valores republicanos e comprometidos com a justiça social, as liberdades e a igualdade. Em 5 de outubro de 2018 a Constituição completa 30 anos, permitindo à comunidade jurídica nacional (e - por que não? - internacional) promover um balanço sobre os avanços e retrocessos alcançados nessas três primeiras décadas de vida da Constituição Cidadã. 
O fortalecimento (ou, para falar com mais sinceridade: o agigantamento) do Poder Judiciário, com a assunção de funções que antes tradicionalmente não lhe competiam; as relações imbricadas (ou, para falar com maior precisão: muitas vezes espúrias) entre o Poder Executivo e o Poder Legislativo num sistema político caracterizado como "presidencialismo de coalizão"; a questão (ou, para falar com maior franqueza: a chaga) da corrupção no âmbito das instituições públicas e privadas e os mecanismos para o seu controle; as tentativas de superar (ou, para falar com maior clareza: de escamotear) um passado de governos autoritários e ditatoriais, que ainda assombram as práticas institucionais no país; todos esses são temas que ensejam a necessidade de uma aprofundada reflexão a propósito do constitucionalismo brasileiro pós-88.

Por essa razão, a presente edição lança o Dossiê Temático "The 30 ${ }^{\text {th }}$ Anniversary of the 1988 Brazilian Constitution", dedicado a leituras dos 30 anos da Constituição da República Federativa do Brasil realizadas por pesquisadores de outros países, como uma forma de oferecer ao público-leitor uma visão do constitucionalismo brasileiro advinda de um olhar estrangeiro. Esta seção especial é composta por 10 artigos redigidos em inglês por autores vinculados a instituições do Chile, Canadá, Colômbia, Egito, Estados Unidos, México e Turquia, sendo dois deles em coautoria com professores brasileiros. A sua organização ficou a cargo de Richard Albert, Professor de Direito Constitucional da University of Texas at Austin (EUA) e Editor Associado da Revista de Investigações Constitucionais, e duas Editoras Convidadas (Guest Editors): Sofia Ranchordás, Professora de European and Comparative Public Law e Rosalind Franklin Fellow da University of Groningen (Holanda) e Mariana Velasco Rivera, J.S.D. Candidate da Yale Law School (EUA). A eles, registramos os nossos mais profundos agradecimentos pelo empenho, atenção e cuidado que tiveram ao organizar esse dossiê especial em um momento tão importante do constitucionalismo brasileiro. Agradecemos, igualmente, pelo estudo introdutório "A moment to mark: the Brazilian Constitution turns 30", que desenvolveram com o escopo de apresentar os artigos do dossiê temático.

Este é também um momento importante para a Revista de Investigações Constitucionais, que com esta edição - a $15^{\text {a }}$ de sua história - completa 5 anos de existência desde a sua fundação. Nesse período, a revista manteve-se sempre em ascensão, buscando aprimorar cada vez mais a qualidade da seleção de artigos, a editoração dos números, as boas práticas editoriais, a internacionalização dos autores e dos pareceristas e a indexação do periódico em bases de dados, indexadores e fontes de informação de renome. É com muito orgulho que constatamos que, em 5 anos de funcionamento, publicamos artigos de autores vinculados a instituições de 23 países diferentes: Albânia, Austrália, Argentina, Brasil, Canadá, Chile, Colômbia, Cuba, Egito, Estados Unidos, Espanha, França, Itália, Israel, Japão, México, Paraguai, Peru, Reino Unido, Rússia, Turquia, Uruguai e Venezuela. No sistema Qualis Periódicos da CAPES, principal instrumento de avaliação de revistas científicas no país, alcançamos o estrato A1 (o mais elevado 
de 8 níveis de classificação). A revista já se encontra indexada na Web of Science e no Scopus, e foi aceita para indexação no SciELO e no Redalyc, todos esses indexadores considerados de excelência no cenário internacional global e latino-americano.

É preciso registrar, nesta oportunidade, um especial agradecimento ao Luzardo Faria, assistente editorial da Revista de Investigações Constitucionais, pelo excepcional trabalho que vem desempenhando em prol do periódico desde a sua fundação, sem o qual esta revista não funcionaria, bem como à Tuany Baron de Vargas, pelos trabaIhos desempenhados nos 3 primeiros anos de existência da revista, que permitiram a construção de um periódico atento às exigências das bases de dados e indexadores nacionais e internacionais.

Esta edição inaugura a seção de "Resenhas", até então inexistente na revista. Por sugestão do Professor Juliano Zaiden Benvindo, da Universidade de Brasília, decidimos criá-la como forma de promover a divulgação de obras relevantes na área do Direito Público no âmbito nacional e internacional. E para atuar como editor da nova seção, nada melhor do que quem sugeriu criá-la! Assim, damos as boas-vindas ao Professor Juliano Benvindo como Book Reviews Editor da Revista de Investigações Constitucionais, o qual lança, também nesta edição, a resenha da recente (e já clássica) obra Unconstitutional constitutional amendments: the limits of amendment power, do Professor Yaniv Roznai, publicada pela Oxford University Press em 2017.

Neste número, o terceiro do ano de 2018, publicamos artigos em 2 idiomas (inglês e português), de autores vinculados a 18 instituições de ensino superior de 9 países diferentes: Chile, Canadá, Colômbia, Egito, Estados Unidos, Irlanda, México, Turquia e de 5 diferentes unidades federativas da República Federativa do Brasil, com representação das regiões Sudeste, Centro-Oeste e Nordeste: Minas Gerais, Rio de Janeiro, São Paulo, Distrito Federal e Pernambuco. Dos trabalhos publicados, 78\% são de Professores Doutores, $78 \%$ redigidos em língua estrangeira, 78\% dos artigos possuem entre seus autores pesquisadores estrangeiros e 100\% dos autores são exógenos ao Estado do Paraná. São eles:

\section{Dossiê - The $30^{\text {th }}$ Anniversary of the 1988 Brazilian Constitution}

- The Brazilian Constitution of 1988 and its ancient ghosts: comparison, history and the ever-present need to fight authoritarianism

\section{Fernando José Gonçalves Acunha}

Professor of Constitutional Law at Centro Universitário de Brasília - UniCEUB (Brasília-DF, Brazil)

\section{Mohamed A. Arafa}

Adjunct Professor at the Indiana University (Indianopolis, United States of America) and the Alexandria University (Alexandria, Egypt)

\section{Juliano Zaiden Benvindo}

Professor of Constitutional Law at University of Brasília (Brasília-DF, Brazil) 
- Transforming the legislative: a pending task of Brazilian and Colombian constitutionalism

\section{Santiago García-Jaramillo}

Professor of Constitutional Theory at Universidad de La Sabana (Chía, Colombia) and Constitutional Law at Pontificia Universidad Javeriana (Bogotá, Colombia)

\section{Camilo Valdivieso-León}

Assistant Professor of International Investment Law at Universidad de Los Andes (Bogotá, Colombia)

- Constitutional amendments and constitutional core values: the Brazilian case in a comparative perspective

\section{Valentina Rita Scotti}

Post-doctoral fellow in Comparative Public Law at Koç University School of Law (Istanbul, Turkey)

- Making Brazil work? Brazilian coalitional presidentialism at 30 and its post-Lava Jato prospects

\section{Andrea Scoseria Katz}

Ph.D. in Political Science at Yale University (New Haven, United States of America)

- Constitutionalizing umbrella-concepts: peace and conflict in the Brazilian Constitution

\section{Alba Ramos Escobar}

Profesor at El Colegio de Veracruz (Xalapa-Enríquez, México)

- Beyond futebol and language: What have we missed from not paying Brazilian constitutionalism its due attention? Reflections from Chile

\section{Pablo Contreras}

Assistant professor at Universidad Alberto Hurtado (Santiago, Chile)

\section{Domingo Lovera}

Assistant professor at Universidad Diego Portales (Santiago, Chile).

- The Brazilian Constitution of 1988: a comparative appraisal

\section{Arturo Alvarado}

Professor at the Center for Sociological Studies (Ciudad de México, México)

- Social rights interpretation in Brazil and South Africa

\section{Evan Rosevear}

PhD Candidate at the Department of Political Science at University of Toronto (Toronto, Canada)

- Constitutionalizing abortion in Brazil

Marta Rodriguez de Assis Machado

Professor at Getúlio Vargas Foundation Law School (São Paulo- SP, Brazil)

\section{Rebecca J. Cook}

Professor emerita at University of Toronto, Faculty of Law (Toronto, Canada) 
- Constitutionalism and rights protection in Mexico and Brazil: comparative remarks

\section{Francisca Pou Giménez}

Professor of Law at Instituto Tecnológico Autônomo do México (Ciudad de México, México)

\section{Artigos}

- Abortion, the Irish Constitution, and constitutional change

\section{David Kenny}

Assistant Professor of Law at Trinity College Dublin (Dublin, Ireland)

- Constitucionalismo popular: modelos e críticas

\section{José Ribas Vieira}

Professor Titular da Universidade Federal do Rio de Janeiro (Rio de Janeiro- RJ, Brasil). Professor Associado da Pontifícia Universidade Católica do Rio de Janeiro (Rio de Janeiro-RJ, Brasil)

\section{Lilian Márcia Balmant Emerique}

Professora adjunta da Faculdade Nacional de Direito e do Programa de Pós-Graduação em Direito da Universidade Federal do Rio de Janeiro (Rio de Janeiro-RJ, Brasil)

\section{Jônatas Henriques Barreira}

Mestre em Direito Constitucional pela Universidade Federal Fluminense (Rio de Janeiro-RJ, Brasil)

- Desafios ao constitucionalismo na América Latina: uma visão geral sobre o "novo golpismo"

\section{João Paulo Allain Teixeira}

Professor do Programa de Pós-Graduação em Direito na Universidade Católica de Pernambuco (Recife-PE, Brasil). Professor Adjunto da Universidade Federal de Pernambuco (Recife-PE, Brasil) Natalia Martinuzzi Castilho

Doutoranda em Direito pela Universidade Católica de Pernambuco (Recife-PE, Brasil). Professora do curso de Direito do Centro Universitário Christus (Fortaleza-CE, Brasil)

- O mito de Marbury v. Madison: a questão da fundação da supremacia judicial Michele Carvalho Santos

Mestranda em Direito pela Faculdade de Direito do Sul de Minas (Pouso Alegre-MG, Brasil)

\section{Leandro Corrêa de Oliveira}

Professor do Mestrado em Direito da Faculdade de Direito do Sul de Minas (Pouso Alegre-MG, Brasil)

Esperamos no futuro passar por muitos outros aniversários - da Constituição de 1988 e da Revista de Investigações Constitucionais - com a expectativa de termos inúmeras razões para comemorar. Viva a Constituição de 1988! Viva a Revista de Investigações Constitucionais!

Curitiba, setembro de 2018.

Prof. Dr. Daniel Wunder Hachem

Editor-Chefe da Revista de Investigações Constitucionais 